\title{
The tuf3 gene of Streptomyces coelicolor A3(2) encodes an inessential elongation factor Tu that is apparently subject to positive stringent control
}

\author{
Gilles P. van Wezel, ${ }^{1,2}$ Eriko Takano, ${ }^{1}$ Erik Vijgenboom, ${ }^{2}$ Leendert Bosch ${ }^{2}$ \\ and Mervyn J. Bibb'
}

\begin{abstract}
Author for correspondence: Gilles P. van Wezel. Tel: +44 1603 452571. Fax: +44 1603456844. e-mail: gilles.vanwezel@bbsrc.ac.uk
\end{abstract}

1 Department of Genetics, John Innes Centre, Colney, Norwich NR4 7UH, UK

2 Department of Biochemistry, Gorlaeus Laboratories, Leiden University, PO Box 9502, 2300RA Leiden, The Netherlands
In Streptomyces coelicolor A3(2), two genes, tuf1 and tuf3, encode the apparent polypeptide chain elongation factors EF-Tu1 and EF-Tu3, respectively. While tuf1 appears to code for the major EF-Tu, the function of tuf3 is unknown. To assess the role of EF-Tu3, tuf3 was subjected to mutational and transcriptional analyses. Replacement of the 5'-half of tuf 3 by an antibiotic resistance cassette had no detectable effect on phenotype, indicating that tuf 3 is not essential for growth or differentiation. The transcription start site of tuf3 was located approximately $195 \mathrm{nt}$ upstream of the translation start site. The sequence of the tuf3 promoter $\left(P_{\text {tuf }}\right)$ resembles the consensus for the major class of eubacterial promoters, and $P_{\text {turf }}$ was recognized preferentially by an RNA polymerase fraction enriched in $\sigma^{\text {hrde, }}$, the principal $\sigma$ factor of $S$. coelicolor. Nuclease $S 1$ mapping failed to reveal tuf3 transcripts during growth of S. coelicolor in liquid culture, consistent with the apparent absence of EFTu3 in total protein extracts of the same strain. However, tuf 3 transcription was observed in cultures of S. coelicolor M145 shortly after nutritional shiftdown (which resulted in the disappearance of tuf1 transcripts) and after addition of serine hydroxamate, both of which induce the stringent response. Transcription of tuf 3 was also observed in transition-phase and stationaryphase cultures of S. coelicolor J1681, a strain deleted for bIdA (which specifies

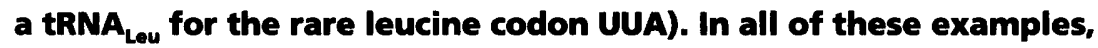
transcription of tuf 3 followed the production of ppGpp, consistent with the hypothesis that tuf 3 is subject to positive stringent control.

Keywords: elongation factor Tu, tuf3, Streptomyces coelicolor A3(2), stringent control, ppGpp

\section{INTRODUCTION}

The polypeptide chain elongation factor Tu (EF-Tu), responsible for delivering amino-acyl tRNAs to the translating ribosome, is one of the most abundant proteins in micro-organisms: it can constitute up to $10 \%$ of total cell protein in rapidly growing Escherichia coli cells (van der Meide et al., 1983). Two tuf genes, tuf $A$ and tufB,

Abbreviations: 2-dog, 2-deoxyglucose; EF-Tu, elongation factor Tu; SHX, serine hydroxamate; Spc, spectinomycin; Str, streptomycin; Thio, thiostrepton.

The GenBank accession number for the tuf3 sequence reported in this paper is $X 77040$. encode EF-Tu in E. coli, and are very similar in nucleotide sequence. The Gram-positive actinomycete Streptomyces ramocissimus produces the antibiotic kirromycin, which binds specifically to EF-Tu, and possesses three tuf genes, designated $t u f 1, t u f 2$ and tuf3. EF-Tu1 and EF-Tu2 show $85 \%$ amino acid sequence identity, and both of them share about $65 \%$ amino acid sequence identity with EFTu3 (Vijgenboom et al., 1994). While tuf1 encodes the major elongation factor EF-Tu1, the roles of tuf 2 and $t u f 3$ are unknown: polyclonal antibodies raised against EFTu2 and EF-Tu3 that had been produced in E. coli failed to detect either protein in extracts of $S$. ramocissimus cultures grown under a variety of conditions (Vijgenboom et al., 1994). While tuf2 appears to be absent 
from most Streptomyces species, Streptomyces coelicolor A3(2) and many other streptomycetes contain close homologues of both tuf1 and tuf3 (van Wezel, 1994). Like tuf $A$ of $E$. coli, tuf1 of $S$. coelicolor is located in the str operon (van Wezel et al., 1994a, 1995), and is well-separated from tuf3 on the physical map of the $S$. coelicolor chromosome (van Wezel et al., 1995). While EF-Tu1 is abundant in $S$. coelicolor, EF-Tu3 could not be detected (van Wezel et al., 1994a).

The stringent response, which was first characterized as a rapid reduction in stable RNA synthesis upon amino acid starvation, is a pleiotropic response to the accumulation of uncharged tRNAs, and there is considerable evidence to suggest that the highly phosphorylated nucleotide ppGpp plays a key role in mediating stringent control (Cashel \& Rudd, 1987). E. coli tuf $A$ and tufB are subject to negative stringent control in response to amino acid starvation, with enhanced ppGpp levels coinciding with severely reduced levels of transcription of both genes (Reeh et al., 1976). S. coelicolor also undergoes the stringent response (Takano \& Bibb, 1994), which can be elicited either by nutritional shiftdown or by addition of serine hydroxamate (SHX; a competitive inhibitor of seryltRNA synthetase), and is characterized by ppGpp synthesis and a rapid decrease in the level of transcription of rRNA genes (Strauch et al., 1991). Although the role of ppGpp in mediating the growth rate control of gene expression remains controversial (Hernandez \& Bremer, 1990, 1993; Gaal \& Gourse, 1990), recent evidence has implicated the highly phosphorylated nucleotide in stationary phase gene expression in E. coli (Gentry et al., 1993). Interestingly, antibiotic production in streptomycetes is generally limited to stationary phase, and mutants of a number of Streptomyces species that are deficient in ppGpp synthesis are also deficient in antibiotic production, leading to the suggestion that ppGpp might serve as a general trigger for antibiotic biosynthesis (Ochi, 1986, 1987; Takano \& Bibb, 1994, and references therein). Furthermore, there is a reasonably good correlation in $S$. coelicolor between ppGpp synthesis and the transcription of antibiotic pathway-specific regulatory genes (Takano \& Bibb, 1994).

In an attempt to determine the role of tuf 3 in $S$. coelicolor, we have inactivated the gene by replacing part of it with an antibiotic resistance determinant. The transcription start site of tuf 3 was identified by in vitro and in vivo analyses, and transcription of tuf 3 was monitored during growth in liquid culture and after induction of the stringent response, either by nutritional shiftdown or by addition of SHX. The results suggest that tuf 3 is an inessential gene that is subject to positive stringent control.

\section{METHODS}

Bacterial strains and plasmids. S. coelicolor strains M145 (prototrophic, SCP1- SCP2- ; Hopwood et al., 1985), J1501 (bis $A 1$ ura $A 1$ str $A 1 \mathrm{Pgl}^{-}, \mathrm{SCP} 1^{-} \mathrm{SCP} 2^{-}$; Chater et al., 1982), $\mathrm{J} 1501 \Delta$ glk $A$ (E. Vijgenboom, unpublished data) and J1681 (J1501 $\Delta$ bld $A$; Leskiw et al., 1993) were obtained from the John
Innes Centre strain collection. E. coli JM101 (Messing et al., 1981) was the host for pUC18 (Yanisch-Perron et al., 1985) and constructs derived from it.

pISCT3-1, pISCT3-2 and pISCT3-U1 were made by cloning fragments of the $S$. coelicolor tuf3-containing plasmid pBSCT3-1 (van Wezel et al., 1994a) via pUC18 into the $x y l$-based promoter-probe vector pIJ4083 (Clayton \& Bibb, 1990). Plasmid inserts were: PvuII-MluI $(-500 /+1700)$ in pISCT3-1, KpnI-MluI $(-260 /+1700)$ in pISCT3-2 and PstI-KpnI $(-1900 /-5)$ in pISCT3-U1 (Fig. 2). In each construct, tuf 3 or its upstream region was inserted in $\mathrm{pIJ} 4083$ in the same orientation as $x y l E$ (Zukowski et al., 1983). However, since the constructs pISCT3-1 and pISCT3-2 also contain $500 \mathrm{bp}$ of sequence downstream of $t u f 3$, these constructs were not used for promoter probing.

The strain used for tuf 3 inactivation was $S$. coelicolor J1501 $\Delta g l k, A$, and the gene replacement vector was pIJ2559, a $12.2 \mathrm{~kb}$ construct derived from pBR329 (Covarrubias \& Bolivar, 1982) that is unable to replicate in Streptomyces since it lacks an appropriate origin of replication (Fig. 1). In this construct the aad $A$ gene (Prentki \& Krisch, 1984), which confers spectinomycin (Spc) and streptomycin (Str) resistance on both E. coli and Streptomyces, is flanked on one side by the $-1900 /-260$ tuf 3 upstream region and on the other by the $3.6 \mathrm{~kb}$ fragment containing the second half of tuf3 and $3 \mathrm{~kb}$ of downstream sequence. Thus a double recombination event will replace the $-260 /+600$ segment of tuf 3 by aad $A$. Additional selectable markers on pIJ2559 are tsr [conferring thiostrepton (Thio) resistance in Streptomyces], cloned as a $1 \mathrm{~kb} B c / \mathrm{I}$ fragment from pI J4083, and $g / k . A$ encoding glucose kinase, which was available as a $1.3 \mathrm{~kb}$ Pst I fragment on the plasmid pI J2423 (Angell et al., 1994). J1501 $\Delta g l k A$ is resistant to 2-deoxyglucose (2-dog), but the presence of the pIJ2559-derived glk $A$ renders this strain 2dog-sensitive. Successful inactivation of tuf 3 by the required double crossover results in loss of both $t s r$ and $g l k A$, yielding a Thio ${ }^{\text {S }} 2-\operatorname{dog}^{\mathbf{R}}$ phenotype.

Culture conditions. Surface-grown cultures were cultivated on R2YE or on minimal medium (MM) agar plates, using glucose or mannitol as the carbon source (Hopwood et al., 1985). Liquid cultures were grown in a minimal medium supplemented with Casamino acids (SMM; Takano et al., 1992), or in yeast extract/malt extract medium (YEME) with $0.5 \%$ glycine (Hopwood et al., 1985), and were inoculated at a density of $5 \times 10^{6}$ c.f.u. $\mathrm{ml}^{-1}$ and grown at $30^{\circ} \mathrm{C}$ with vigorous shaking (300 r.p.m. $\min ^{-1}$ ). Reproducibly dispersed growth was obtained, with a doubling time of $2.2 \mathrm{~h}$ in SMM and $1.9 \mathrm{~h}$ in YEME. In SMM, rapid transition into stationary phase occurred approximately $14 \mathrm{~h}$ after inoculation (Strauch et al., 1991). Nutritional shiftdown and treatment with $25 \mathrm{mM}$ SHX were performed as described by Strauch et al. (1991).

Promoter-probe experiments. The $x y l E$ gene from Pseudomonas putida (Zukowski et al., 1983) present in pIJ4083 (Clayton \& Bibb, 1990) was used as a reporter gene for in vivo promoter activity. Transformants containing pISC'T3-U1 were grown on R2YE and MM (Hopwood et al., 1985) in the presence of $10 \mu \mathrm{g}$ Thio $\mathrm{ml}^{-1}$ (a gift from Bristol-Meyers Squibb). Plates were sprayed with $0.5 \mathrm{M}$ catechol after $1,2,3$ and $4 \mathrm{~d}$ growth and the amount of catechol converted into yellow 2-hydroxymuconic semialdehyde by catechol 2,3-dioxygenase was assessed visually.

In vitro transcription analysis. RNA polymerase was isolated from a culture of $S$. coelicolor M145 in the transition between exponential growth and stationary phase, as described previously by Buttner \& Brown (1985), and partially separated into different holoenzyme forms by Superose-6 FPLC. In vitro run-off 


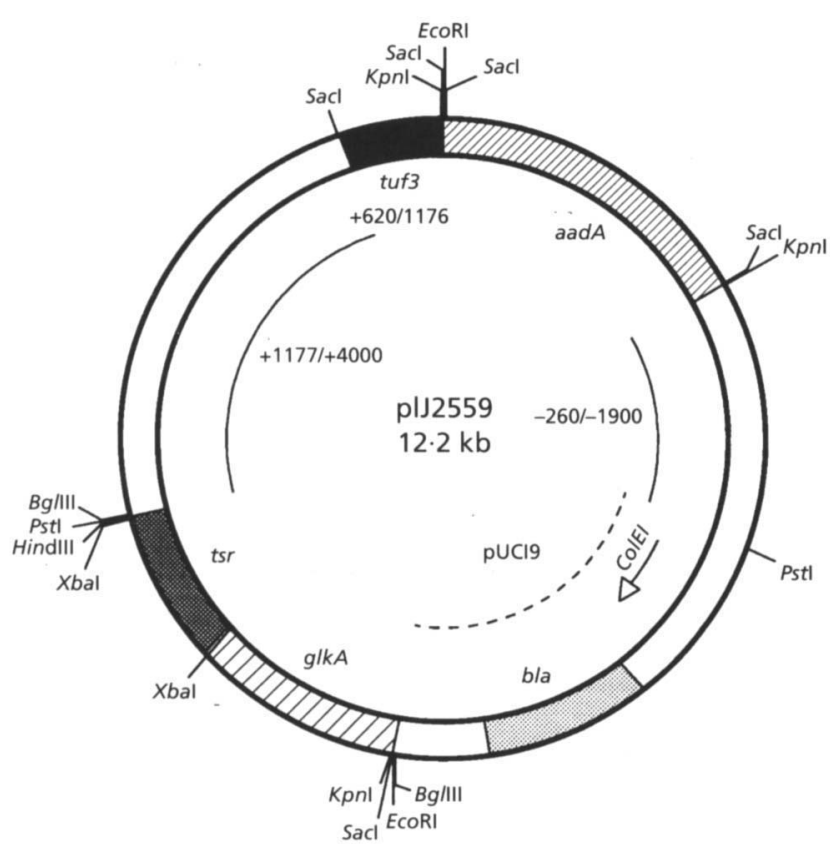

Fig. 1. Restriction map of plJ2559. Numbers refer to nt positions in the complete tuf3 clone (PBSCT3-1), and are relative to the tuf3 translation start site. ColE1, origin of replication E1 (from pBR322); aadA, Spc/Str resistance gene; bla, ampicillin resistance gene; glkA, glucose kinase gene; tsr, Thio resistance gene.

transcription experiments were performed as described by Buttner \& Brown (1985). Products were analysed on denaturing $6 \%(\mathrm{w} / \mathrm{v})$ polyacrylamide gels using ${ }^{32} \mathrm{P}$-end-labelled $\mathrm{HpaII}$ fragments of pBR322 as size markers. The 600 bp PvuII-StyI $(-500 /+100)$ fragment and the $360 \mathrm{bp}$ KpnI-StyI
$(-260 /+100)$ fragment were isolated from pISCT3-1 and pISCT3-2, respectively (Fig. 2), and used as templates.

RNA isolation. RNA was isolated from M145, J1501 or J1681 according to Hopwood et al. (1985). To remove residual DNA, the RNA was salt-precipitated in $3 \mathrm{M} \mathrm{NaOAc}$ (pH 6.0). The RNA samples were then treated with DNaseI $\left(1 \mathrm{~h}\right.$ at $37^{\circ} \mathrm{C}$ with $0 \cdot 1 \mathrm{U}$ DNaseI per $50 \mathrm{ml}$ initial culture sample), extracted with a $1: 1$ mixture of phenol/chloroform (saturated with $100 \mathrm{mM}$ Tris, $\mathrm{pH} 7.0$ ) and precipitated in $0.4 \mathrm{M} \mathrm{NaOAc}(\mathrm{pH} \mathrm{6.0)}$ with 2-propanol. The RNA was resuspended in water and the concentration was determined spectrophotometrically.

Nuclease 51 mapping. Hybridization of $10 \mu \mathrm{g}$ RNA with the appropriate DNA probe was performed according to Murray (1986) in NaTCA buffer (Summerton et al., 1983). All subsequent steps were carried out as described previously by Strauch et al. (1991), using an excess of probe. The $600 \mathrm{bp}$ PvuII-StyI fragment from pISCT3-1 (Fig. 2), ${ }^{32} \mathrm{P}$-labelled at the 5 ' end of the StyI site, was used for mapping tuf 3 transcripts; the 25 bp non-homologous extension upstream of the PvuII site allowed discrimination between DNA-RNA hybrids and reannealed probe. The $530 \mathrm{bp} S \mathrm{maI}-\mathrm{XboI}(-70 /+460)$ fragment from pASCT1-1 (van Wezel et al., 1994a; Fig. 2), ${ }^{32} \mathrm{P}$ labelled at the $5^{\prime}$ end of the XhoI site, was used for mapping $t$ f 1 transcripts. The 558 bp FspI-HincII fragment, corresponding to $n t$ positions -708 to -151 with respect to the $5^{\prime}$ end of the $16 \mathrm{~S} r \mathrm{RNA}$ coding sequence and ${ }^{32} \mathrm{P}$-labelled at the $5^{\prime}$ end of the $H$ incII site, was used for mapping $\operatorname{rn} A$ transcripts (van Wezel et al., 1994b).

ppGpp measurements. ppGpp levels were determined as described by Strauch et al. (1991).

\section{RESULTS}

\section{Inactivation of tuf3 by gene replacement}

To study the role of $t u f 3$ in S. coelicolor we inactivated the gene by replacing the segment of tuf 3 that extends from -260 to +600 (with respect to the translation start site of

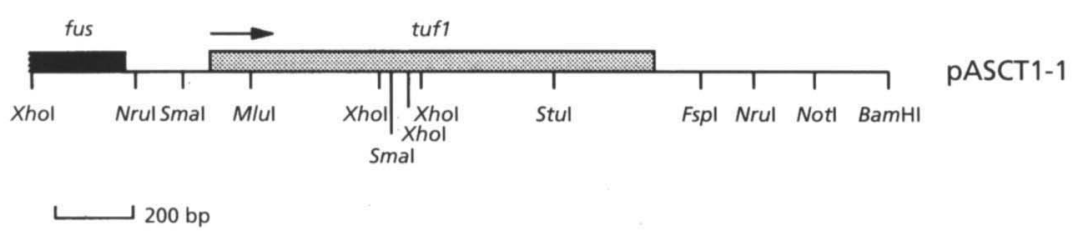

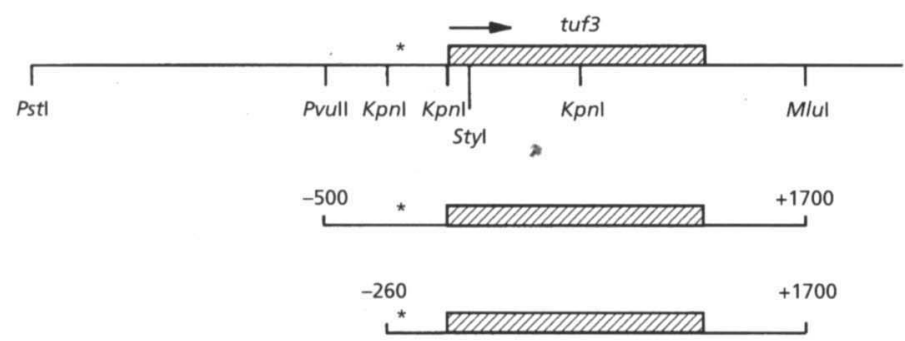

$-1900+\frac{-5 x y l E}{}$

\section{pISCT3-1}

pISCT3-2

\author{
pISCT3-U
}

Fig. 2. S. coelicolor tuf constructs. Only the plasmid inserts are shown. fus (which encodes EF-G) and tuf1 are part of the S12 (str) operon, and were cloned in PAT153 (Twigg \& Sherratt, 1980) to give pASCT1-1 (van Wezel et al., 1994a); only part of the insert is shown. The tuf3 constructs were made by inserting fragments into the multiple cloning site of plJ4083. Only pISCT3-U1 was used for promoter-probing. 1 Numbers above inserts correspond to nt positions relative to the translation start site of tuf3. Arrows show the direction of transcription. *, Transcription start site of tuf3. 


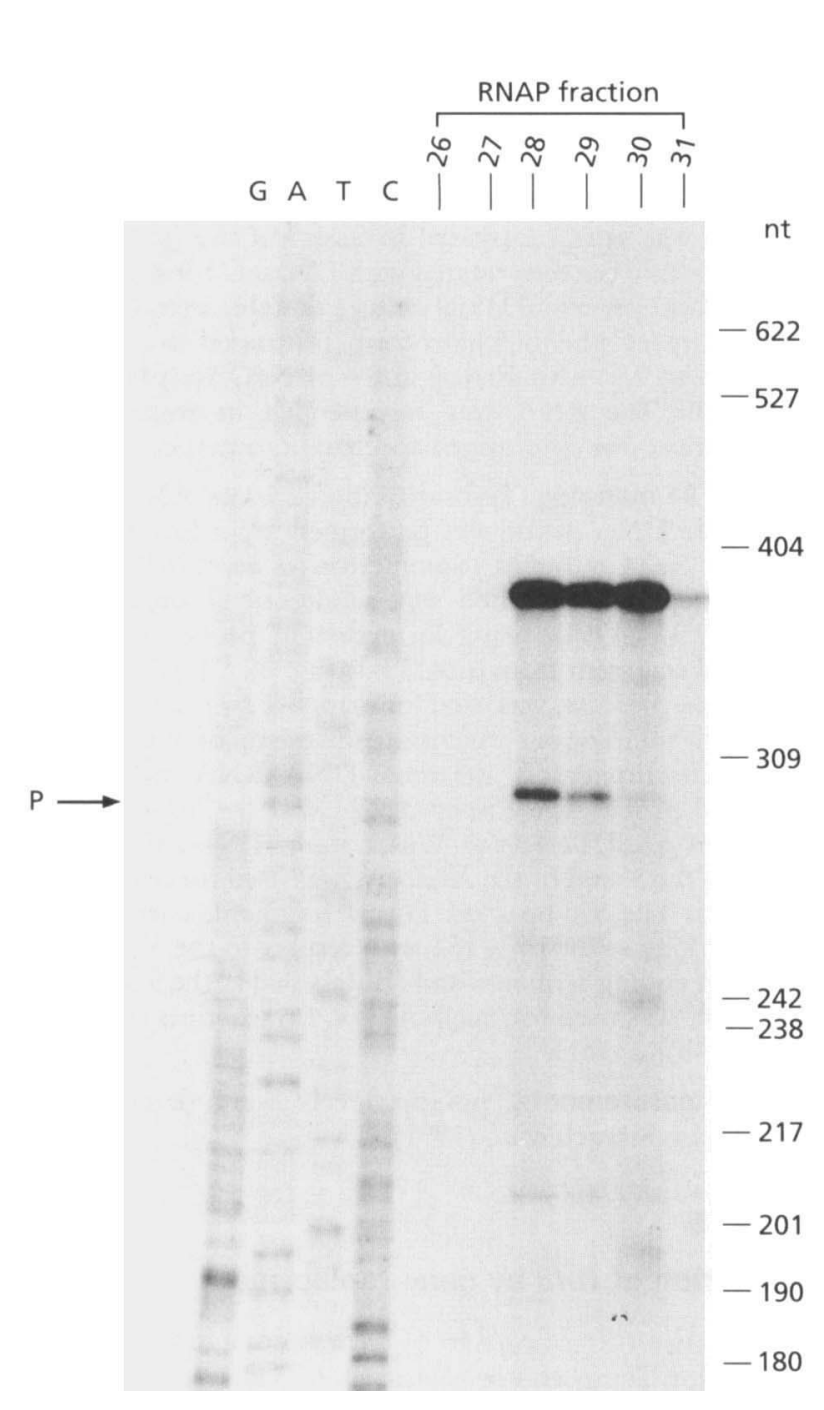

Fig. 3. In vitro transcription analysis of $S$. coelicolor tuf3. $P$, Run-off transcript originating at $P_{\text {tuf }}$; RNAP fraction, RNA polymerase fractions eluting from a Superose-6 FPLC column. The right-hand side of the figure shows a DNA size marker (denatured Hpall-digested pBR322) in nt. GATC, tuf3 nt sequence ladder generated using a $19 \mathrm{nt}$ primer whose $5^{\prime}$ end corresponds precisely to the $5^{\prime}$ end of the labelled probe used for 51 nuclease mapping (see Methods).

tuf3) with an antibiotic resistance gene (aad) that confers resistance to Spc and Str. This resulted in the deletion of the tuf 3 promoter (see later) and ribosome-binding site, and of protein-coding sequences essential for EF-TU function (van Wezel et al., 1994a). Protoplasts of $S$. coelicolor J1501 $\Delta$ glk $A$ (glk $A$ encodes glucose kinase which confers sensitivity to $2-\mathrm{dog}$ ) were transformed with the tuf 3 disruption construct pIJ2559 (see Methods and Fig. 1), selecting for resistance to Thio, Spc and Str. Resistant colonies were likely to have arisen from single-crossover integration of the plasmid into the tuf 3 region of the chromosome. Spores from five of the 20 independent pIJ2559 transformants obtained were plated on MM containing 2-dog and Spc to select for the second crossover event, which removed glk. $A$ and $t s r$, and AAGCGTCGGCGATGATCTGTCTCÄTGTTCCGGTACGCCTTCCACCTCGCA GCATCCGCGGTCGCGGATGCCCCGAAGGCTGCCGTCGCCCACTTCACCGC

\section{$-117$}

$-67$

CCGCAGGGGGAGGGTCGGCCGGCCCCAGGGGTCCCCACCACCGCCCACGA SD

-17 GGCTTCGAGGTACCGCCATGTCCAAGACGGCGTACGTCCGCACCAAACCG $\begin{array}{llllllllllllllll}M & S & K & T & A & Y & V & R & T & K & P\end{array}$

Fig. 4. Nucleotide sequence of the region upstream of the tuf3 structural gene. Numbering refers to nt position relative to the tuf3 translation start site (chosen as +1 ). Putative promoter consensus sequences are underlined. Dots above the sequence refer to alternative transcription start sites of tuf3. An $8 \mathrm{nt}$ $A+T$-rich stretch preceding the promoter is shown in bold typeface. The deduced amino acid sequence at the start of EFTu3 is shown below the sequence; the putative Shine-Dalgarno sequence (SD) preceding tuf 3 is represented in italics.

resulted in replacement of the $5^{\prime}$ half of $t u f 3$ by aad $A$. Five putative tuf 3 mutants were screened by three Southern hybridizations, with probes recognizing aad $A$ (Fig. 1), the N-terminal part of $t u f 3$ that should have been deleted, and the part of tuf 3 that should have remained. All five isolates did indeed lack the $5^{\prime}$-half of the tuf 3 gene and gave the expected hybridization patterns with all three probes. Since they also had all of the expected genetic markers (resistant to 2-dog and Spc, sensitive to Thio and unable to grow on glucose as a carbon source), they were considered to be tuf 3 deletion mutants. The mutants were indistinguishable from the parental strain $\mathrm{J} 1501 \Delta g l k A$ in their growth rates, colony morphology and ability to produce the pigmented secondary metabolites actinorhodin and undecylprodigiosin, and no morphological abnormalities could be detected at the microscopic level.

\section{Expression of the tuf 3 promoter occurs in surface- grown cultures when present on a high-copy- number plasmid}

M145 transformants containing the multi-copy plasmid pISCT3-U1, which has the $-1900 /-5$ region (relative to the translation start site) of $t u f 3$ in front of $x y l E$ (Fig. 2), gave colonies that rapidly became yellow when sprayed with catechol after $2 \mathrm{~d}$ growth on solid MM containing mannitol as carbon source. After $4 \mathrm{~d}$, spraying with catechol produced bright-yellow aerial hyphae. This suggests that catechol dioxygenase production (i.e. $x y / E$ transcription) takes place in both vegetative and aerial mycelium, although the pigmentation of the aerial hyphae might have been the result of diffusion of the yellow compound from the vegetative mycelium (diffusion of the product of XylE activity, the yellow compound 2hydroxymuconic semialdehyde, into the agar was also clearly apparent). Interestingly, pISCT3-U1 transformants produced neither aerial mycelium nor the pigmented antibiotics actinorhodin and undecylprodigiosin on MM with glucose or on R2YE plates, even 


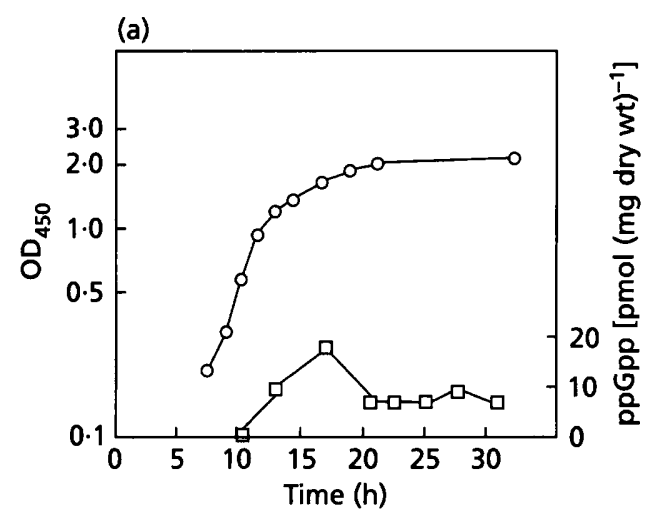

Fig. 5. Comparison of tuf1 and rnA transcription in $S$. coelicolor M145. (a) Growth curve (O) and ppGpp production ( $\square$ ) of a SMM-grown culture. (b) Transcription of tuf1 and rrnA. tuf1, fulllength protection of the tuf1 probe; rrnA P1 and $r r n A$ P2, transcripts initiated at the $r r n A$ $\mathrm{P} 1$ and $\mathrm{P} 2$ promoters, respectively. $\mathrm{M}, \mathrm{DNA}$ size marker as in Fig. 3 ; $C$, control lane $(30 \mu \mathrm{g}$ tRNA). Times indicate hours after inoculation with germinated spores.

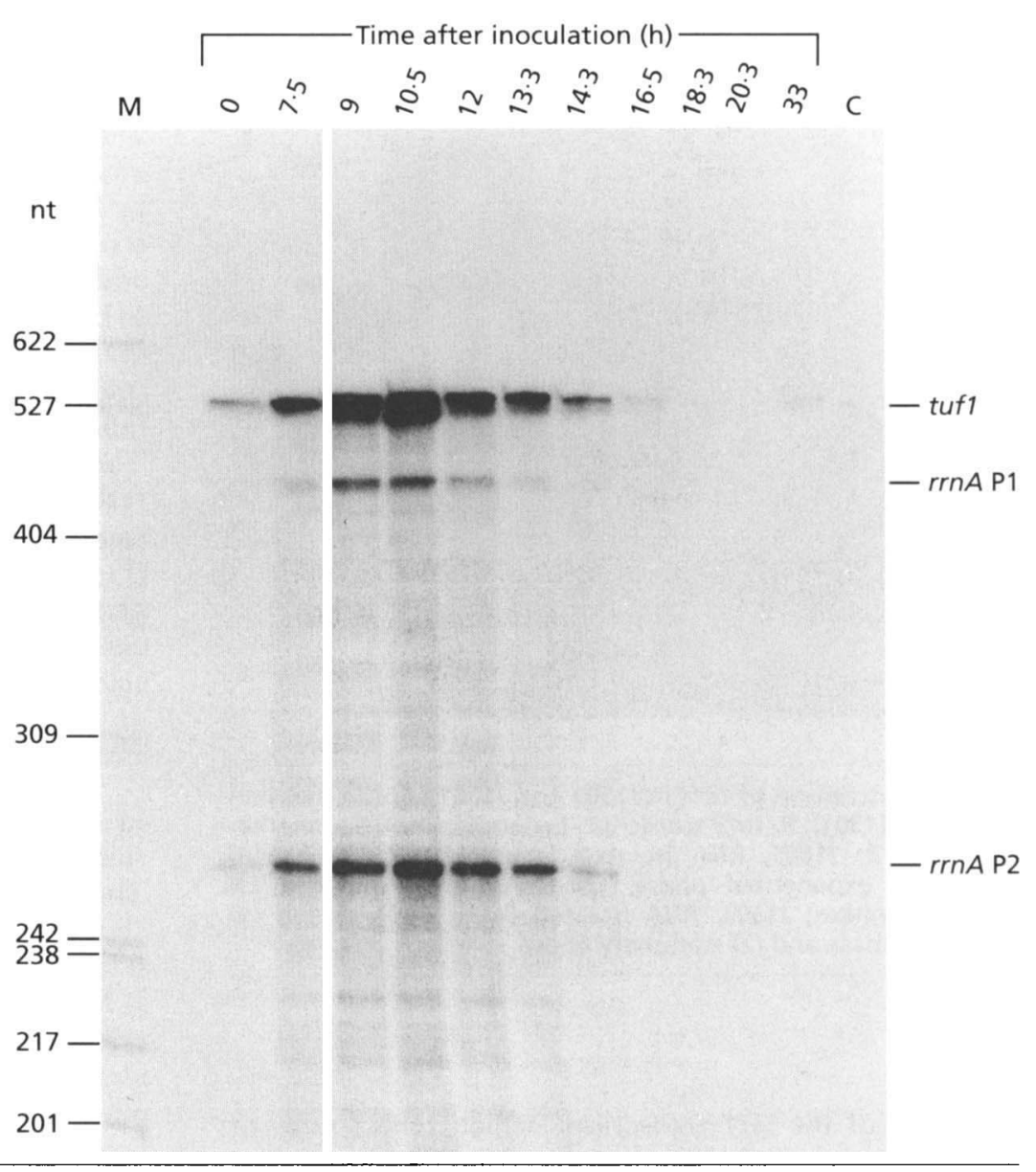

after prolonged incubation at $30^{\circ} \mathrm{C}$, a phenotype comparable to that of an $S$. coelicolor bld $A$ mutant (Lawlor et al., 1987). M145 transformants containing pISCT3-1 or pISCT3-2 displayed normal growth and differentiation, regardless of the medium used.

\section{In vitro transcription of tuf3}

RNA polymerase from a transition phase culture of $S$. coelicolor M145, partially fractionated into different holoenzyme forms by Superose-6 FPLC, was used in in vitro run-off transcription assays to identify promoters in the tuf 3 upstream region. The PvuII-StyI $(-500 /+100)$ and the KpnI-StyI $(-260 /+100)$ fragments were used as templates. Since both fragments gave identical results, only those obtained with the $K p n I-S t y I$ template are shown (Fig. 3). In each case, two major transcripts were observed. One corresponded to the size of the template and was probably the result of end-to-end transcription. The second band (designated $\mathrm{P}$ in Fig. 3) corresponded to a transcript of approximately $295 \mathrm{nt}$ and suggests a transcription start site around nt position - 195 (with respect to the translation start site), which was confirmed by nuclease S1 mapping (see below). The putative transcription start site is preceded by the sequences TCGACG and GATGAT, separated by 17 bp (Fig. 4), which resemble the consensus -35 and -10 sequences, respectively, for the major class of eubacterial promoters.
In $S$. coelicolor, such sequences appear to be recognized by $\sigma^{\text {hrdB }}$ (Brown et al., 1992), whose activity was most abundant in RNA polymerase fraction 28 (data not shown), the one that gave the strongest signal for $\mathrm{P}_{\text {tuf } 3}$ (Fig. 3).

\section{Transcription of tuf1 and tuf 3 during liquid culture}

To establish the level and timing of tuf 3 transcription in vivo, RNA from M145 and J1501 cultures grown in SMM was analysed by nuclease S1 mapping using the $620 \mathrm{bp}$ PvuII-StyI fragment as probe. Growth of, and ppGpp production by, the M145 culture used for RNA isolation are shown in Fig. 5(a). No protection of the tuf 3 probe was observed. We also analysed the transcription of tuf1 in the $S$. coelicolor M145 culture, using the same RNA preparations. tuf1 lies in the S12 ribosomal protein operon (van Wezel et al., 1994a, 1995) and, by analogy to E. coli (Lindahl \& Zengel, 1986, and references therein), is likely to be transcribed from a promoter upstream of $r p s L$ (encoding S12). For mapping of tuf1 transcripts we used the 530 bp SmaI-XboI $(-70 /+460)$ fragment from pASCT1-1 (van Wezel et al., 1994a), uniquely endlabelled at the $X$ hoI site, as probe (Fig. 2), and therefore expected full-length protection of the probe. Since different probes were used, strict quantitative comparisons are not possible, but it is interesting to note that 


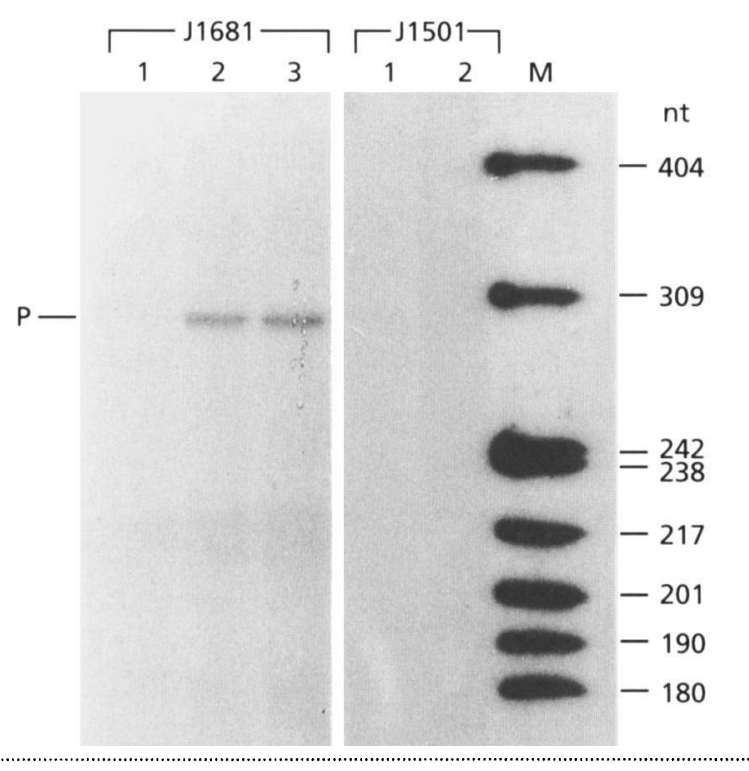

Fig. 6. Transcription of tuf 3 in $J 1501$ and $J 1681$ (a b/dA deletion mutant of J1501). $P$, tuf3 transcript. Lanes: $M$, DNA size marker as in Fig. 3; J1681, RNA isolated from J1681 (J1501 $\Delta$ b/dA) during (1) exponential phase, (2) transition phase and (3) stationary phase; J1501, RNA isolated from J1501 during (1) transition phase and (2) stationary phase.

the levels of the tuf1 transcripts, which reflect rates of synthesis and degradation, were considerably higher than those derived from the $\operatorname{rrn} A \mathrm{P} 1$ and $\mathrm{P} 2$ promoters (Fig. $5 \mathrm{~b})$, even though $\mathrm{P} 2$ is the strongest promoter of the $\operatorname{rrn} A$ operon (van Wezel et al., 1994b). The control, $30 \mu \mathrm{g}$ tRNA, failed to protect the probe, indicating that the fulllength protection was not due to probe reannealing. Transcripts corresponding to tuf1 and $\operatorname{rrn} A$ were barely detectable approximately $16 \mathrm{~h}$ after inoculation, corresponding to early stationary phase. Thus, transcription of tuf1 shows the same growth-phase dependence as $\operatorname{rrn} A$.

\section{tuf3 transcription in the b/dA deletion mutant J1681}

Interestingly, nuclease $\mathrm{S} 1$ mapping using RNA from $\mathrm{J} 1681$, a bld $A$ deletion mutant of J1501 defective in the formation of aerial mycelium and spores, showed tuf 3 transcripts in this strain (Fig. 6), but only after prolonged exposure of the autoradiograms. While no signal was detected during exponential phase (Fig. 6, J1681, lane 1), a band was detected in RNA isolated from lateexponential-phase and stationary-phase cultures. The $295 \mathrm{nt}$ protected fragment corresponds in size to the transcript observed in the in vitro run-off transcription assays (Fig. 3). The transcription initiation site for the corresponding promoter is around nt position -195 relative to the tuf 3 translation start site. We failed to detect tuf 3 transcripts during transition phase in the congenic bld $A^{+}$strain J1501 (Fig. 6, J1501, lanes 1 and 2, respectively), consistent with the data obtained for M145.

\section{tuf 3 is transcribed after nutritional shiftdown and after addition of SHX}

Since transcription of $E$. coli $\operatorname{tuf} A$ and $\operatorname{tuf} B$ is negatively stringently controlled (Reeh et al., 1976), we analysed how tuf 1 and tuf 3 transcription responded to amino acid starvation provoked by either nutritional shiftdown or by addition of SHX. Nutritional shiftdown of an S. coelicolor M145 culture at an $\mathrm{OD}_{450}$ of 0.6 led to a marked increase in the level of ppGpp, with a maximum of about $200 \mathrm{pmol}$ (mg dry weight) ${ }^{-1} 15 \mathrm{~min}$ after shiftdown (Fig. 7a), falling to $45 \mathrm{pmol}$ (mg dry weight) ${ }^{-1} 2 \mathrm{~h}$ after shiftdown. The culture continued growing (albeit at a slow rate) and reached stationary phase 6-7 h after shiftdown. tuf1 transcripts were barely detectable $30 \mathrm{~min}$ after shiftdown (Fig. 7b), suggesting that expression of the major EF-Tu gene of $S$. coelicolor is also subject to negative stringent control. Reappearance of $t u f 1$ transcripts $4.8 \mathrm{~h}$ after amino acid depletion presumably reflects adaptation to the new growth rate and the turnover of excess EF-Tu1 present after shiftdown.

In contrast, tuf 3 transcripts appeared within $30 \mathrm{~min}$ of shiftdown, and reached a maximum after $1 \mathrm{~h}$ (Fig. 7c). The amount of $t u f 3$ transcript under these conditions was about ten times higher than that in transition-phase and stationary-phase cultures of J1681 (comparable amounts of RNA were used in each experiment, and autoradiogram exposure times were typically ten times longer for identification of the tuf 3 transcripts in J1681 than after nutritional shiftdown of M145). tuf 3 transcripts were barely detectable $3 \mathrm{~h}$ after shiftdown of M145.

The stringent response can also be elicited by treatment with SHX, although lower levels of ppGpp are induced than after nutritional shiftdown $[75$ and $200 \mathrm{pmol}$ (mg dry weight $)^{-1}$, respectively; Fig. 8a]. While addition of SHX leads to a marked reduction in the level of rRNA transcripts (Strauch et al., 1991), addition of SHX to a final concentration of $50 \mathrm{mM}$ led to the appearance, within $30 \mathrm{~min}$, of low-abundance tuf 3 transcripts (Fig. $8 \mathrm{~b})$.

\section{DISCUSSION}

tuf3 deletion mutants were not noticeably affected in growth or differentiation, demonstrating that EF-Tu3 does not play an essential role in the Streptomyces life-cycle. Western blotting using antibodies raised against the highly homologous $S$. ramocissimus EF-Tu3 failed to identify the $t u f 3$ gene product in total protein extracts isolated from M145 after nutritional shiftdown (van Wezel, 1994). This suggests that EF-Tu3, if present at all in $S$. coelicolor, occurs only in trace amounts, even when tuf 3 transcripts can be detected.

The XylE ${ }^{+}$phenotype of pISCT3-U1 revealed a promoter within 1900 bp of the tuf 3 translation start site. Earlier work (van Wezel, 1994) had shown that M145 containing pISCT3-2, which has only 260 bp of sequence upstream of tuf3, produces EF-Tu3 in the absence of any additional 
(a)

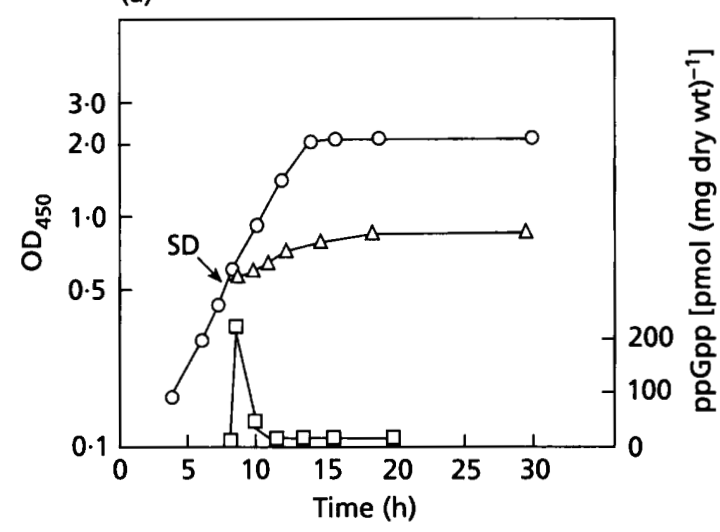

(c)

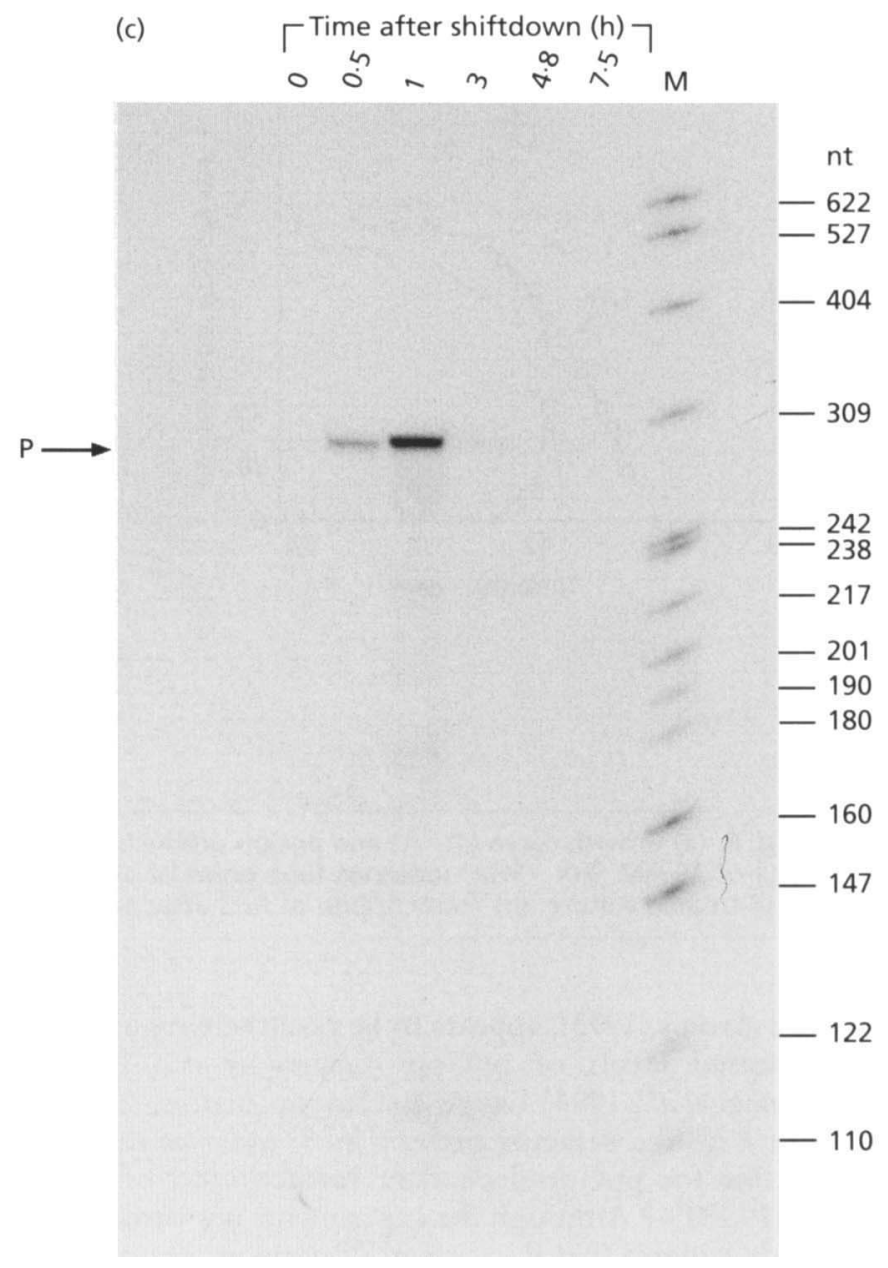

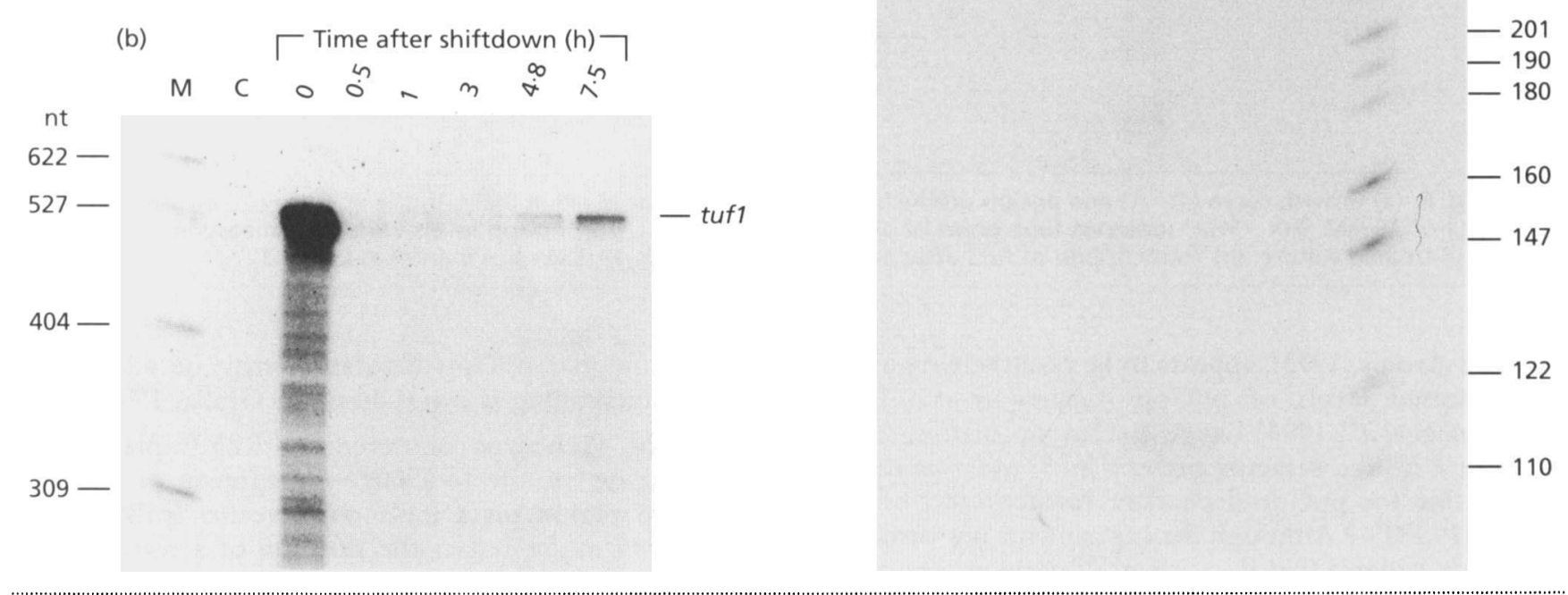

Fig. 7. Transcription of tuf1 and tuf3 after nutritional shiftdown of S. coelicolor M145. (a) Growth curve $(\triangle, O)$ and ppGpp production $(\square)$ of a SMM-grown culture, with $(\triangle)$ and without $(O)$ nutritional shiftdown (SD) at an $O D_{450}$ of 0.6. (b) Transcription of tuf1 after nutritional shiftdown. (c) Transcription of tuf3 after shiftdown. P, tuf3 transcripts initiated at the tuf3 promoter around nt position - 195; M, DNA size marker as in Fig. 3; C, control lane (30 $\mu$ g tRNA).

promoter. Therefore it is possible that the strong $x y l E$ expression observed with pISCT3-U1 may be entirely due to a promoter located within 260 bp of the tuf 3 translation start site.

In vitro run-off transcription assays with $S$. coelicolor $\mathrm{RNA}$ polymerase revealed a transcription initiation site at approximately nt position -195 relative to the tuf 3 translation start site. The sequence of the putative tuf 3 promoter (TCGACG - $17 \mathrm{bp}$-GATGAT; Fig. 4) shows an 8 out of $12 \mathrm{nt}$ match with the consensus sequences for the major class of eubacterial promoters (TTGACA - $17 \mathrm{bp}$ - TATAAT; Hawley \& McClure, 1983). The RNA polymerase fraction that yielded the highest level of tuf 3 transcription in vitro (Fig. 3) was enriched in RNA polymerase containing $\sigma^{\text {hrdB }}$, consistent with recognition by $\sigma^{\text {hrdB }}$ in vivo. The tuf 3 promoter is preceded by a stretch of seven As and one T (Fig. 4), a very unusual sequence in the $\mathrm{G}+\mathrm{C}$-rich streptomycetes. Similar A + T-rich sequences found approximately $45 \mathrm{bp}$ upstream of the transcription start site of various $E$. coli promoters were shown to interact with the $\alpha$ subunit of
RNA polymerase, resulting in a stimulation of transcription (Ross et al., 1993). The A + T-rich stretch near the tuf 3 promoter lies at a similar position, and it is possible that this sequence is involved in $\alpha$-dependent transcriptional activation.

tuf 3 transcripts appeared immediately after invoking the stringent response, either after nutritional shiftdown or after addition of SHX, suggesting that transcription of tuf 3 may be subject to positive stringent control, which may also be true for the histidine biosynthetic operon of Salmonella typhimurium (Rudd et al., 1985; Cashel \& Rudd, 1987). Another gene that may be subject to positive stringent control in S. coelicolor is actII-ORF4 (FernándezMoreno et al., 1991), the putative activator gene for the actinorhodin biosynthetic pathway (Takano \& Bibb, 1994). However, in contrast to tuf 3 , actII-ORF4 transcripts can be detected in stationary-phase cultures of M145. Whether ppGpp plays a causal role in triggering the expression of these genes remains an open question. Interestingly, expression of rpoS, which encodes the stationary-phase-specific $\sigma$ factor $\sigma^{\mathrm{S}}$ of E. coli (reviewed by 
(a)

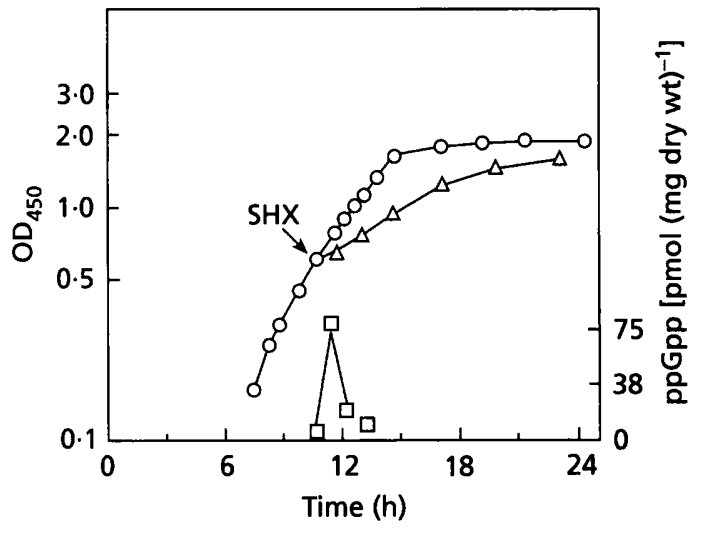

(b)

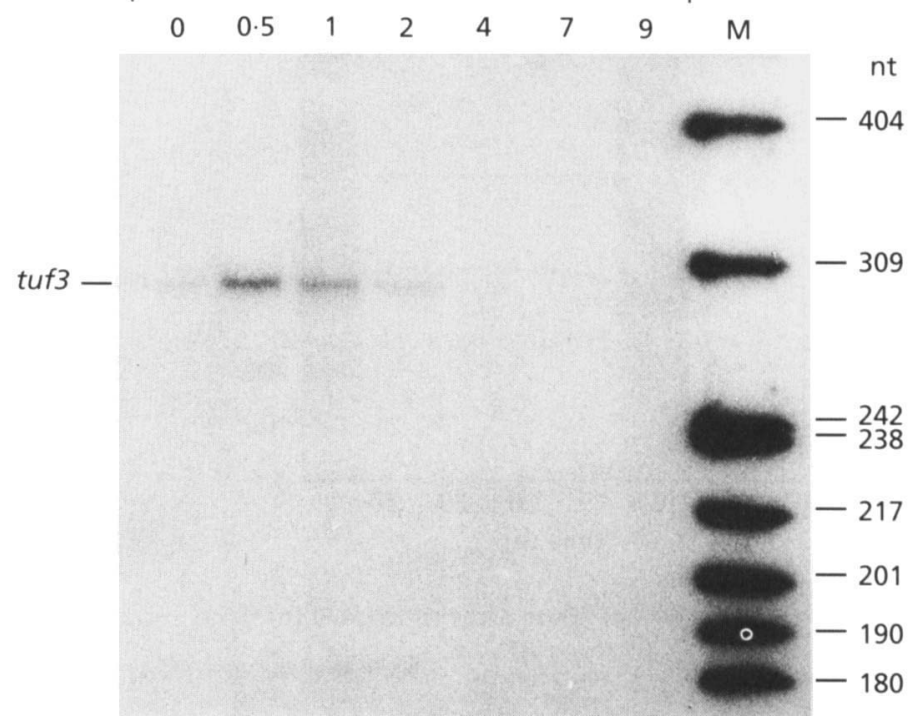

Fig. 8. (a) Growth curve $(O, \triangle)$ and ppGpp production $(\square)$ by S. coelicolor M145 in SMM, in the absence $(O)$ or presence $(\triangle)$ of $25 \mathrm{mM}$ SHX. 'SHX' indicates time point of addition of $\mathrm{SHX}\left(\mathrm{OD}_{450} 0.6\right)$. ppGpp levels were only measured in the SHX-treated culture. (b) Transcription of tuf3 after addition of $25 \mathrm{mM}$ SHX. M, DNA size marker as in Fig. 3.

Hengge-Aronis, 1993), appears to be positively regulated by increased levels of ppGpp (Gentry et al., 1993; Takayanagi et al., 1994; Lange \& Hengge-Aronis, 1994). Is there a $\sigma^{\mathrm{s}}$-like $\sigma$ factor present in $S$. coelicolor that is responsible for ppGpp-dependent transcription of tuf 3 and actII-ORF4? Although the experiments performed in this study suggest that $\mathrm{P}_{\text {tuf } 3}$ is a $\sigma^{\text {hrdB }}$-type promoter, $E$. coli $\sigma^{\mathrm{S}}$ and $\sigma^{70}$ (the major $\sigma$ factor of $E$. coli) show overlapping promoter specificities (Tanaka et al., 1993).

A low level of tuf 3 transcription was observed in lateexponential and stationary-phase cultures of the bld $A$ deletion mutant $\mathrm{J} 1681$, but not in its $b l d A^{+}$progenitor J1501. If ppGpp does play a role in activating tuf 3 transcription, perhaps the sensitivity of the tuf 3 promoter to ppGpp is enhanced in the bld $A$ mutant; alternatively, perhaps bld $A$ mutants have elevated levels of ppGpp, reducing the incremental increase required to activate $t u f 3$ transcription.

While tuf1 transcripts were abundant during exponential growth, roughly coinciding with transcription from the rrn $A \mathrm{P} 1$ and $\mathrm{P} 2$ promoters, transcription of tuf 3 was not observed in unstressed cultures. However, the tuf 3 upstream region gave a high level of $x y l E$ expression when cloned in a multi-copy promoter-probe plasmid, and high levels of EF-Tu3 had been observed previously in transformants containing either pISCT3-1 or pISCT32 (van Wezel, 1994). These multi-copy effects might reflect repression of $t u f 3$ by a protein that is readily titrated out when $t u f 3$ is present at high-copy-number. Alternatively, differences in the extent of DNA supercoiling of the chromosomally and plasmid-located tuf 3 promoters may (partly) explain the discrepancy in their activity: the degree of DNA supercoiling is known to influence the effect of ppGpp on transcription initiation in vitro, suggesting that ppGpp regulation may be affected by DNA supercoiling in vivo (Ohlsen \& Gralla, 1992).

The bald phenotype observed on R2YE plates after introduction of the $-1900 /-5$ segment of the tuf 3 upstream region on a multi-copy vector (pISCT3-U1) into M145 might reflect the titration of a transcription factor required for differentiation by a regulatory element contained in the cloned fragment. Other DNA fragments have been cloned that inhibit or prevent differentiation when present in S. coelicolor in multiple copies, most of which probably sequester proteins involved in development of aerial hyphae or spores (Champness \& Chater, 1994). Examples are the putative $\sigma^{\text {whiG }}$-dependent promoters $\mathrm{P}_{\mathrm{TH} 4}$ and $\mathrm{P}_{\mathrm{TH} 270}$, which probably titrate out this $\sigma$ factor, leading to absence of sporulation (Tan \& Chater, 1993). pISCT3-U1 overlaps pISCT3-1 by $500 \mathrm{bp}$ at the tuf3-proximal end, and pISCT3-1 displayed normal growth and differentiation on R2YE; thus the putative regulatory element cannot be located near the tuf 3 promoter, and hence it seems unlikely that it is involved in regulation of $t u f 3$ transcription.

\section{ACKNOWLEDGEMENTS}

We thank Gabriella Kelemen for help with microscopy and for discussions, Mark Buttner for advice on in vitro run-off transcription assays, and Keith Chater and David Hopwood for valuable comments on the manuscript. This work was partly supported by a short-term fellowship from EMBO to G.P.V.W.

\section{REFERENCES}

Angell, S., Lewis, C. G., Buttner, M. J. \& Bibb, M. J. (1994). Glucose repression in Streptomyces coelicolor A3(2): a likely regulatory role for glucose kinase. Mol \& Gen Genet 244, 135-143. 
Brown, K. L., Wood, S. \& Buttner, M. J. (1992). Isolation and characterization of the major vegetative RNA polymerase of Streptomyces coelicolor A3(2); renaturation of a sigma subunit using GroEL. Mol Microbiol 6, 1133-1139.

Buttner, M. J. \& Brown, N. L. (1985). RNA polymerase-DNA interactions in Streptomyces. In vitro studies of a S. lividans plasmid promoter with $S$. coelicolor RNA polymerase. $J$ Mol Biol 185, 177-188.

Cashel, M. \& Rudd, K. E. (1987). The stringent response. In Eschericbia coli and Salmonella typhimurium: Cellular and Molecular Biology, pp. 1410-1438. Edited by F. C. Neidhardt, J. L. Ingraham, K. Brooks Low, B. Magasanik, M. Schaechter \& H. E. Umbarger. Washington, DC: American Society for Microbiology.

Champness, W. C. \& Chater, K. F. (1994). Regulation and integration of antibiotic production and morphological differentiation in Streptomyces spp. In Regulation of Bacterial Differentiation, pp. 61-93. Edited by P. Piggot, P. Youngman \& C. Moran. Washington, DC: American Society for Microbiology.

Chater, K. F., Bruton, C. J., King, A. A. \& Suarez, J. E. (1982). The expression of Streptomyces and Escherichia coli drug-resistance determinants cloned into the Streptomyces phage $\phi \mathrm{C} 31$. Gene 19, 21-33.

Clayton, T. M. \& Bibb, M. J. (1990). Streptomyces promoter-probe plasmids that utilise the $x y l E$ gene of Pseudomonas putida. Nucleic Acids Res 18, 1077.

Covarrubias, L. \& Bolivar, F. (1982). Construction and characterization of new cloning vehicles. VI. Plasmid pBR329, a new derivative of pBR328 lacking the 482-base-pair inverted duplication. Gene 17, 79-89.

Fernández-Moreno, M. A., Caballero, J. L., Hopwood, D. A. \& Malpartida, F. (1991). The act cluster contains regulatory and antibiotic export genes, direct targets for translational control by the bld $A$ transfer RNA gene of Streptomyces. Cell 66, 769-780.

Gaal, T. \& Gourse, R. L. (1990). Guanosine-3'-diphosphate 5'diphosphate is not required for growth rate-dependent control of rRNA synthesis in Escherichia coli. Proc Natl Acad Sci USA 87, 5533-5537.

Gentry, D. R., Hernandez, V. J., Nguyen, L. H., Jensen, D. B. \& Cashel, M. (1993). Synthesis of the stationary-phase sigma factor $\sigma^{\mathrm{S}}$ is positively regulated by ppGpp. J Bacteriol 175, 7982-7989.

Hawley, D. K. \& McClure, W. R. (1983). Compilation and analysis of Escherichia coli promoter DNA sequences. Nucleic Acids Res 11, 2237-2255.

Hengge-Aronis, R. (1993). Survival of hunger and stress: the role of rpoS in early stationary phase gene regulation in E. coli. Cell 29, 165-168.

Hernandez, V. J. \& Bremer, H. (1990). Guanosine tetraphosphate (ppGpp) dependence of the growth rate control of $r r n B$ P1 promoter activity in Escherichia coli. J Biol Chem 265, 11605-11614.

Hernandez, v. J. \& Bremer, H. (1993). Characterization of RNA and DNA synthesis in Escherichia coli strains devoid of ppGpp.J Biol Chem 268, 10851-10862.

Hopwood, D. A., Bibb, M. J., Chater, K. F., Kieser, T., Bruton, C. J., Kieser, H. M., Lydiate, D. J., Smith, C. P., Ward, J. M. \& Schrempf, H. (1985). Genetic Manipulation of Streptomyces: a Laboratory Manual. Norwich: John Innes Foundation.

Lange, R. \& Hengge-Aronis, R. (1994). The cellular concentration of the $\sigma^{\mathrm{s}}$ subunit of RNA polymerase in Escberichia coli is controlled at the level of transcription, translation, and protein stability. Genes \& Dev 8, 1600-1612.

Lawlor, E. J., Baylis, H. A. \& Chater, K. F. (1987). Pleiotropic morphological and antibiotic deficiencies result from mutations in a gene encoding a tRNA-like product in Streptomyces coelicolor A3(2). Genes \& Dev 1, 1305-1310.

Leskiw, B. K., Mah, R., Lawlor, E. J. \& Chater, K. F. (1993). Accumulation of bld $A$-specified tRNA is temporally regulated in Streptomyces coelicolor A3(2). J Bacteriol 175, 1995-2005.

Lindahl, L. \& Zengel, J. M. (1986). Ribosomal genes in Eschericbia coli. Annu Rev Genet 20, 297-326.

van der Meide, P., Vijgenboom, E., Talens, A. \& Bosch, L. (1983). The role of EF-Tu in the expression of $t u f A$ and $t u f B$ genes. Eur $J$ Biochem 130, 397-407.

Messing, J., Crea, R. \& Seeburg, P. H. (1981). A system for shotgun DNA sequencing. Nucleic Acids Res 9, 309-321.

Murray, M. G. (1986). Use of sodium trichloroacetate and mung bean nuclease to increase sensitivity and precision during transcript mapping. Anal Biochem 158, 165-170.

Ochi, K. (1986). Occurrence of the stringent response in Streptomyces sp. and its significance for the initiation of morphological and physiological differentiation. J Gen Microbiol 132, 2621-2631.

Ochi, K. (1987). Metabolic initiation of differentiation and secondary metabolism by Streptomyces griseus: significance of the stringent response (ppGpp) and GTP content in relation to A factor. $J$ Bacteriol 169, 3608-3626.

Ohlsen, K. L. \& Gralla, J. D. (1992). Interrelated effects of DNA supercoiling, ppGpp, and low salt on melting within the Escherichia coli rrnB $\mathrm{P}_{1}$ promoter. Mol Microbiol 6, 2243-2251.

Prentki, P. \& Krisch, H. M. (1984). In vitro insertional mutagenesis with a selectable DNA fragment. Gene 29, 303-313.

Reeh, S., Pedersen, S. \& Friesen, J. D. (1976). Biosynthetic regulation of individual proteins in $\mathrm{rel}^{+}$and $\mathrm{rel} A$ strains of Escherichia coli during amino acid starvation. Mol \& Gen Genet 149, 279-289.

Ross, W., Gosink, K. K., Salomon, J., Igarashi, K., Zhou, C., Ishihama, A., Severinov, K. \& Gourse, R. L. (1993). A third recognition element in bacterial promoters: DNA binding by the subunit of RNA polymerase. Science 262, 1407-1412.

Rudd, K. E., Bochner, B. R., Cashel, M. \& Roth, J. R. (1985). Mutations in the spoT gene of Salmonella typhimurium: effects on bis operon expression. J Bacteriol 163, 534-542.

Strauch, E., Takano, E., Baylis, H. A. \& Bibb, M. J. (1991). The stringent response in Streptomyces coelicolor A3(2). Mol Microbiol 5, 289-298.

Summerton, J., Atkins, T. \& Bestwick, R. (1983). A rapid method for preparation of bacterial plasmids. Anal Biochem 133, 79-84.

Takano, E. \& Bibb, M. J. (1994). The stringent response, ppGpp and antibiotic production in Streptomyces coelicolor A3(2). Actinomycetes 8, 1-16.

Takano, E., Gramajo, H. C., Strauch, E., Andres, N., White, J. \& Bibb, M. J. (1992). Transcriptional regulation of the redD transcriptional activator gene accounts for growth-phase-dependent production of the antibiotic undecylprodigiosin in Streptomyces coelicolor A3(2). Mol Microbiol 5, 289-298.

Takayanagi, Y., Tanaka, K. \& Takahashi, H. (1994). Structure of the $5^{\prime}$ upstream region and the regulation of the rpoS gene of Escherichia coli. Mol \& Gen Genet 243, 525-531.

Tan, H. \& Chater, K. F. (1993). Two developmentally controlled promoters of Streptomyces coelicolor A3(2) that resemble the major class of motility-related promoters in other bacteria. J Bacteriol 175 , 933-940.

Tanaka, K., Takayanagi, Y., Fujita, N., Ishihama, A. \& Takahashi, H. (1993). Heterogeneity of the principal $\sigma$ factor in Escherichia coli: the $r$ poS gene product, $\sigma^{38}$, is a second principal $\sigma$ factor of RNA 
polymerase in stationary-phase Escherichia coli. Proc Natl Acad Sci US A 90, 3511-3515.

Twigg, A. J. \& Sherratt, D. (1980). Trans-complementable copy number mutants of plasmid ColE1. Nature 283, 216-218.

Vijgenboom, E., Woudt, L. P., Heinstra, P. W. H., Rietveld, K., van Haarlem, J., van Wezel, G. P., Shochat, S. \& Bosch, L. (1994). Three tuf-like genes in the kirromycin producer Streptomyces ramocissimus. Microbiology 140, 983-998.

van Wezel, G. P. (1994). Transcriptional regulation of translational genes in Streptomyces coelicolor A3(2). PhD thesis, University of Leiden, The Netherlands.

van Wezel, G. P., Woudt, L. P., Vervenne, R., Verdurmen, M. L. A., Vijgenboom, E. \& Bosch, L. (1994a). Cloning and sequencing of the tuf genes of Streptomyces coelicolor A3(2). Biochim Biophys Acta 1219, 543-547.

van Wezel, G. P., Krab, I., Douthwaite, S., Bibb, M. J., Vijgenboom, E. \& Bosch, L. (1994b). Transcription analysis of the
Streptomyces coelicolor A3(2) $\operatorname{rrnA}$ operon. Microbiology 140, 3357-3365.

van Wezel, G. P., Buttner, M. J., Vijgenboom, E., Bosch, L., Hopwood, D. A. \& Kieser, H. M. (1995). Mapping of genes involved in macromolecular synthesis on the chromosome of Streptomyces coelicolor A3(2). J Bacteriol 177, 473-476.

Yanisch-Perron, C., Vieira, J. \& Messing, J. (1985). Improved M13 phage cloning vectors and host strains: nucleotide sequences of the M13mp18 and pUC19 vectors. Gene 33, 103-119.

Zukowski, M. M., Gaffney, D. F., Speck, D., Kaufmann, M., Findeli, A., Wisecup, A. \& Lecocq, J.-P. (1983). Chromogenic identification of genetic regulatory signals in Bacillus subtilis based on expression of a cloned Pseudomonas gene. Proc Natl Acad Sci USA 80, 1101-1105.

Received 12 April 1995; revised 27 June 1995; accepted 5 July 1995. 